\title{
The Influence of the Brazil Cost in the Direct Investments in the Country from 2012 to 2018
}

By Daiane Rodrigues Dos Santos, Marco Aurélio Sanfins, Daiana Da Silva Rodrigues, Joyce Oliveira Do Da Silva \& Leonardo Dos Santos Cunha

Veiga de Almeida University

Abstract- Widely used by economists in Brazil; the "Brazil Cost" concept refers to costs that hinder development, as they burden production, removing its competitive character, indispensable in a globalized economy. Brazil Cost may imply major obstacles to Foreign Direct Investment in the Country (FDI) and consequently impact the country's growth and development. The study evaluated the influence of variables that are part of the Brazil Cost in Foreign Direct Investment over the last six years. For this, the DMA - Dynamic Model Averaging methodology was used, which allowed the modeling of the dependent variable, FDI, as a function of its past and other variables dynamically over time. These results contribute to the evaluation of the assumptions made about the relationship between the components of Brazil Cost and the volume of direct investment in the country.

Keywords: brazil cost; direct investments; dynamic model averages; bayesian DMA method; brazilian infrastructure.

GJMBR-B Classification: JEL Code: E22

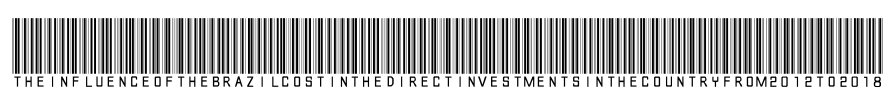

Strictly as per the compliance and regulations of:

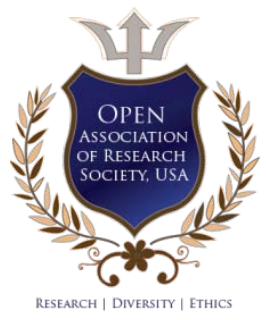

(C) 2019. Daiane Rodrigues Dos Santos, Marco Aurélio Sanfins, Daiana Da Silva Rodrigues, Joyce Oliveira Do Da Silva \& Leonardo Dos Santos Cunha. This is a research/review paper, distributed under the terms of the Creative Commons AttributionNoncommercial 3.0 Unported License http://creativecommons.org/licenses/by-nc/3.0/), permitting all non-commercial use, distribution, and reproduction in any medium, provided the original work is properly cited. 


\title{
The Influence of the Brazil Cost in the Direct Investments in the Country from 2012 to 2018
}

\author{
Daiane Rodrigues Dos Santos ${ }^{\alpha}$, Marco Aurélio Sanfins ${ }^{\sigma}$, Daiana Da Silva Rodrigues ${ }^{\circ}$, \\ Joyce Oliveira Do Da Silva ${ }^{\omega}$ \& Leonardo Dos Santos Cunha ${ }^{*}$
}

Abstract- Widely used by economists in Brazil; the "Brazil Cost" concept refers to costs that hinder development, as they burden production, removing its competitive character, indispensable in a globalized economy. Brazil Cost may imply major obstacles to Foreign Direct Investment in the Country (FDI) and consequently impact the country's growth and development. The study evaluated the influence of variables that are part of the Brazil Cost in Foreign Direct Investment over the last six years. For this, the DMA - Dynamic Model Averaging methodology was used, which allowed the modeling of the dependent variable, FDI, as a function of its past and other variables dynamically over time. These results contribute to the evaluation of the assumptions made about the relationship between the components of Brazil Cost and the volume of direct investment in the country.

Keywords: brazil cost; direct investments; dynamic model averages; bayesian DMA method; brazilian infrastructure.

\section{INTRODUCTION}

rom the decade of 1990, the Brazil Cost has become a topic with great importance that is discussed the main hindrances that break the growth of the country imposing additional costs to the companies. In parallel, the Brazilian economy arises like the country that recaps the flow of the international capitals in the middle of the decade of 1990. Among the extern resources it shows the role of the foreign direct investment (IED), currently known as the direct investment in the country the (IDP), its volume, is from the second half of the decade, it overcome the of the entrance of the capitals in the short term, establishing a significant change in the infrastructure of properties from capital in Brazil.

For Peres and Yamada (2014) the inflow of IED is more and more elevated in the Brazilian economy, and they played a fundamental role throughout the decade of 1990, to seek the support of the volumes deficits of the transactions in the account and the view to the value exchanged after the currency Real Plan.

The objective of this article is to study the influence of the variables that make up the Brazil Cost in

Author $\alpha$ : Department of production engineering, Veiga de Almeida University, Rio de Janeiro, Brazil. e-mail: daianesantoseco@gmail.com Author 6: Department of statistics, Federal Fluminense University Niterói, Brazil.

Author $\rho \omega ¥:$ Department of production engineering, Veiga de Almeida University, Rio de Janeiro, Brazil. the direct investment of the country. It's structured in six topics, starting with the introduction. Intosequence, section 2 is discoursed about the journey of the foreign direct investment (or Direct Investment of the Country) in Brazil. In portion 3 will bring forward the cost in Brazil in the direct investment of the country. Section 4 talks about the influence of Brazil Cost in the direct investment in the country. Section 5 will show the methodology DMA, in section 6, how the methodology is applied and the analysis of the aftermath results. Portion 7 is the conclusion of this article.

\section{The Recent Route of the Foreign Direct Investment in the Country}

According to Carminati and Fernandes (2013), after the middle of the 1990's decade, the flux of foreign direct investment with destiny to Brazil has arisen expressively. According to the authors, in the year in question, Brazil is ranked in a special position in international capital flows, especially how is destined the IDP and how is done in multinationals companies. According to the author, since 2011 the country is among the five main destinies of the fluxes of the IDP in the world.

In the 1990's decade, the investors came back powerfully, except for the years of 1998 and 1999, motivated by the Brazilian economic instability that was reached with the Real Plan, plus the constitutional amendments of 1995 (Santos et al., 2016). These amendments put an end to the monopoly in the departments of telecommunication, oil, and gas, which later made possible the privatization process, which was promoted in the renewal of the flux of the IED for Brazil. Ever since the Brazilian economy started to be more and more destined to these resources, the privatization program made it possible for Brazil to attract the interest and the great record of the entrance of IDP, making the Brazilian economy attractive to the foreign capital.

According to the report of Brazilian Central Bank, the position of the IDP at the end of 2016 reached US\$703 billion $(25,0 \%$ of the gross domestic product PIB). Considering the annual position 2010 a 2016, The maximum value occurred in 2012, US\$731billions (26, $2 \%$ from PIB), and the minimum value was, in 2015 , US $\$ 568$ billion (23, 6\% from PIB). 


\section{BraziL COST}

The Brazil Cost is a term used to describe the group of structural difficulties, bureaucracies and economical that make expensive the investment in Brazil, making it difficult to the national development, the rising unemployment, informal work, tax evasion, and foreign exchange evasion. Being pointed as the set of factors that compromises the competitiveness and the efficiency of the national industry. For Mancuso (2004), the Brazil Cost is an expression used to point factors that affect the competitiveness of domestic companies against companies located in other countries.

The Brazil Cost with its taxation (bureaucracy and tax burden) could contribute to elevating the gap of prices between domestic and imported products. In this article, the Brazilian tax burden is represented for total tax revenues (Coding 7639). The series has monthly frequency and was collected at the site of Brazilian Central Bank.

According to Barbieri et al.(2014), the current scenario of the Brazilian infrastructure presents elevated costs for society in general. The inefficiency of the transport infrastructure as part of this scenario affects the competitively of the economy in a systematic. In this article, we use the series containing the monthly investment of the Ministry of Transport. The data are disclosed in the monthly $\mathrm{CNI}$ reports.

For Barbieri, the rigidity of work legislation and the high social tax incidence on payroll has been common targets from the discussion created about the Brazil Cost.

To represent the social tax, we use a proxy the net monthly revenue of RGPS (the General Regime of Social Security) available on the site of National Treasury.

The price of energy and your evolution are important for the impact it has on the industry and the competitively of the companies. In this article, we will use the cost of the electrical energy of IPCA a proxy for the cost of energy in Brazil. The data are taken from the site of the Brazilian Central Bank.

The working capital is connected to the tax interests of the country that the company is stablished. The taxation interests could affect directly the companies' activity, and it could affect the cost of the working capital origination from third parties. (Banking financing, for example). The SELIC rate considered a basic interest Brazilian tax, which was used to represent the working capital in this article.

The corruption could be seen as an abuse to the politics power to private gain. For Campos and Pereira (2016) the corruption is related to the incentives and to the problems related the main agent where there are problems in the asymmetric of information. In this article, we use one index of search of the web created by google that reflects in the interest of the world over corruption in Brazil. The keywords used was Corruption Brazil. It is important to note that this variable is a proxy. Quantifying concern about corruption in a country isn't an easy task. This is an attempt to quantify this difficult variable to measure.

The components of Brazil Cost the above mentioned are outlined from bibliographic research. Given the difficulty in collecting the data (many exogenous) for the present study, we try to minimize these factors with the use of proxy variables.

\section{The Influence of Brazil Cost in Direct Investments of The Country}

Beginning in the 1990s, a decade marked by the commercial opening, implementation of the Real Plan and privatization of sectors previously owned by the public power, we began to talk about Brazil Cost. This term brings together the detrimental obstacles to the economic growth of the Country, and its existence translates into additional costs to the companies that operate here. Thus, this study has a double objective: to identify the components of this cost and to verify if there is any relation with the entry of Foreign Direct Investment (FDI), category of investment constituted when the investor holds $10 \%$ or more of the common shares or the voting right company.

The Brazil Cost can imply in a great obstacle for the direct foreign investment and consequently the growth of the country. According to Haddad and Hewings (1992), the cost of doing business in Brazil is one of the main obstacles to economic development and reveals the existence of distortions in the relationship between public and private sector, reflected by inadequate and poor legislation provision of the commonweal.

In general, we can say that IDP brings many benefits to the receiving economy. The country that seeks to attract foreign investment tends to improve its business environment by becoming more transparent. A process of self-segregation of the companies, in its process of expansion, showing that only the most productive companies of a country will seek external markets through direct investments. Thus, the presence of international corporations with high productivity in Brazil can contribute to the improvement of national productivity, providing training to employees, and even establishing a high level of competition with domestic firms.

This research has the objective of studying the interference of the components of Brazil Cost in Direct Investment in the Country, and for this; we will use the DMA Methodology - dynamic model averaging. This allows the modeling of the dependent variable - IDP according to its past and other variables dynamically. 
V. Methodology dma - Dynamic Model Averaging

The Dynamic Model Averaging method proposed by Raftery et al. in 2010 considers the uncertainty concerning the models through Bayesian weighting, additionally allows the parameters and weights of the weighting to change in each period. In this way, the parameters of the model can follow the dynamics of the series over time, and the model can adapt according to the economic conjecture.

Considering initially a regression model, one can specify Direct Investment in the Country as being represented by $y_{t}$ and evolving according to the following equation:

$y_{t}=\sum_{k=1}^{p} \theta_{k t} y_{t-k}+\sum_{k=1}^{p} \phi_{k t} x_{t-k}+\varepsilon_{t} \varepsilon_{t} \sim N\left(0, H_{t}\right)$

In this application, $x_{t}$ represents the variables that compose the Brazil Cost and explain the Direct Investment in the Country.

The number of predictive variables can be large and therefore, we may have to deal with many model combinations. Thus, the model selection becomes a major challenge. According to Catania and Nonejad (2016), the DMA methodology provides an ideal way to deal with these sources of uncertainty.

The model presented in equation (1) could be representedin the state space form proposed by Durbin, and Koopman (2012).

Equation of observations:

$$
y_{t}=Z_{t} \alpha_{t}+\varepsilon_{t} \varepsilon_{t} \sim N\left(0, H_{t}\right)
$$

Equation of state:

$$
\alpha_{t}=\alpha_{t-1}+\eta_{t} \eta \sim N\left(0, Q_{t}\right)
$$

That is $t=1, \ldots T, Z_{t}=\left[1, y_{t-h}, x_{t-h}\right]$ are the predictor of variables $\left(y_{t}\right)$ e $\alpha_{t}$ that represent the vector of weightings.

$$
\left(\begin{array}{l}
\varepsilon_{t} \\
\eta_{t}
\end{array}\right) \sim N I D\left(\left(\begin{array}{l}
0 \\
0
\end{array}\right),\left(\begin{array}{cc}
H_{t} & 0 \\
0 & Q_{t}
\end{array}\right)\right)
$$

In other words $\boldsymbol{y}_{\boldsymbol{t}}$ the interest variable, $\boldsymbol{Z}_{\boldsymbol{t}}^{(\boldsymbol{k})} \subseteq$ $\boldsymbol{Z}_{\boldsymbol{t}}, \quad$ with $\quad k=1, \ldots, K, \quad \varepsilon_{t}^{(k)} \sim N\left(0, \boldsymbol{H}_{\boldsymbol{t}}^{(\boldsymbol{k})}\right)$ e $\boldsymbol{\eta}_{\boldsymbol{t}}^{(\boldsymbol{k})} \sim$ $N\left(0, \boldsymbol{Q}_{t}^{(\boldsymbol{k})}\right)$, defines $L_{t} \in\{1,2, \ldots, K)$ that represents each model applied for each period, $\boldsymbol{\Theta}_{\boldsymbol{t}}=\left(\boldsymbol{\alpha}_{\boldsymbol{t}}^{(\mathbf{1})}, \ldots, \boldsymbol{\alpha}_{\boldsymbol{t}}^{(\boldsymbol{k})}\right)^{\prime} \mathrm{e}$ $\boldsymbol{y}^{t}=\left(\boldsymbol{y}_{1}, \ldots, \boldsymbol{y}_{\boldsymbol{t}}\right)^{\prime}$,

$$
\begin{aligned}
& y_{t}=Z_{t}^{(k)} \alpha_{t}^{(k)}+\varepsilon_{t}{ }^{(k)} \\
& \alpha_{t}^{(k)}=\alpha_{t-1}{ }^{(k)}+\eta_{t}{ }^{(k)}
\end{aligned}
$$

The conditional variances, $\boldsymbol{H}_{t}^{(\boldsymbol{k})}$ and $\boldsymbol{Q}_{t}^{(\boldsymbol{k})}$, are unknown. Obviously, when $\boldsymbol{Q}_{t}^{(\boldsymbol{k})}=\mathbf{0}, \boldsymbol{\alpha}_{\boldsymbol{t}}^{(\boldsymbol{k})}$ is constant over time, for $\boldsymbol{Q}_{t}^{(\boldsymbol{k})} \neq \mathbf{0}$, parameters vary over time, have a distinct model for each point in time. According to Peixoto (2017), the equation permits the state of a better model to be kept for a time, so the prediction of time can be $T$ proceeded exploring the information through time $T-1$ calculating the possibility of the posterior model.

The DMA avoids the difficult task of specifying $Q_{t}^{(k)}$ for each individual model because it has a forgetting parameter, $00<\delta \leq 1$. This, in turn, simplifies much from the practical point of view; we just need to worry about $\delta$.

When $\delta$. $=1$ we have $\boldsymbol{Q}_{t}^{(\boldsymbol{k})}=0$, that is, $\alpha_{t}{ }^{(k)}$ is equal to its value at time $t-1$, For $\delta<1$, we introduce time variation in $\alpha_{t}{ }^{(k)}$. According to Catania and Nonejad (2016), when $\delta .=0.99$, in the context of quarterly data, observations five years ago receive approximately $80 \%$ of the weight of the observation of the last period, which corresponds to the gradual time variation in $\alpha_{t}{ }^{(k)}$. According to the authors, when $\delta .=0.95$, the observations from 20 periods ago receive only $35 \%$ of the weight of the observation of the last period, suggesting that a relatively bigger shock reaches the regression coefficients. This, however, increased variability (5) - (6) depends not only on the choice of the predictors in $\boldsymbol{Z}_{\boldsymbol{t}}{ }^{(\boldsymbol{k})}$ but also on the choice of $\boldsymbol{\alpha}_{\boldsymbol{t}}{ }^{(\boldsymbol{k})}$ also results in greater prediction variance. $\delta$.

According to Koop e Korobilis (2012) apud Peixoto (2016), he main advantage in using the default factor oblivion in the equation of the model is that it becomes dispensable the use of the algorithm like MCMC to draw the transition between models.

Conditional to $\delta$., the DMA probability of the model $M_{k}$ is conditional to the current information defined at time $t, \mathbf{z}_{t}$, is then defined as:

$$
p\left(M_{k} \mid \mathbf{Z}_{t}\right)=\frac{p\left(\left(y_{t} \mid M_{k}, \mathrm{Z}_{t-1}\right) p\left(M_{k} \mid \mathrm{Z}_{t-1}\right)\right.}{\sum_{l=1}^{n} p\left(y_{t} \mid M_{l}, \mathrm{Z}_{t-1}\right) p\left(M_{l} \mid \mathrm{Z}_{t-1}\right)}
$$

To which $p\left(M_{k} \mid \mathbf{Z}_{t}\right)$ é a predictive of model $M_{k}$ rated in $y_{t}, \quad p\left(M_{k} \mid Z_{t-1}\right)=p\left(M_{k} \mid Z_{t-1}\right)^{\alpha} / \sum_{l=1}^{n} p\left(y_{t} \mid M_{l}, \mathrm{Z}_{t-1}\right)^{\alpha}$, in which $0<\alpha<1$ is the forgetting factor for the whole model e $p\left(M_{k} \mid \mathrm{Z}_{t-1}\right)$ is the probability of the model at time $t-1$. In many applications $\alpha \in\{0,98,0,99,1\}$ According to Catania and Nonejad (2016), $\alpha \in$ $\{0,98,0,99,1\}$ with works well and generally the results do not change drastically in different values de $\alpha$.

With the evolution of $\boldsymbol{H}_{\boldsymbol{t}}^{(\boldsymbol{k})}$, Koop and Korobilis (2013) it is proposed a simple method in $H_{t}^{(k)}=H^{(i)}$ for all $\mathrm{t}$, in time $t=0$, specifically one priori Normal in $\alpha_{0}{ }^{(k)}$ and a priori transformed Gama one priori Gama inversed in $H^{(i)}$, i,e, $H^{(i)} \mid Z_{0} \sim \mathcal{G} \mathcal{J}\left(\frac{1}{2}, \frac{1}{2} S_{0}^{(k)}\right)$ where $\mathcal{G} \mathcal{J} \sim$ $\left(\frac{v}{2}, \frac{\kappa}{2}\right)$, being $\mathcal{G} \mathcal{J}$ the distribution of Inverted Range with scale parameter $(v)$ and form $(\kappa)$. A posterior of $H^{(i)}$ 
follows a $\mathcal{G} \mathcal{J}$ distribution with parameters, $S_{t}^{(k)}$ and $n_{t}^{(k)}$, where time testimates of $H^{(i)}$ and $S_{t}^{(k)}$ are given below:

$$
S_{t}^{(k)}=S_{t-1}^{(k)}+\frac{S_{t}^{(k)}}{n_{t}^{(k)}}\left(\frac{e_{t}^{2(k)}}{Q_{t}^{(k)}}-1\right)
$$

$n_{t}^{(k)}=n_{t-1}^{(k)}+1, e_{t}^{(k)}$ e $\mathcal{Q}_{t}^{(k)}$ are related to the Kalman recursions for the i-th DLM model. More information on Kalman's recursions in Catania and Nonejad (2016) and Prado and West (2017). It should be noted that the form of evolution of $H_{t}^{(k)}$ presented in equation (8) is not unique; it can evolve as an exponentially weighted moving average (EWMA), for example.

However, in many applications, allowing the time variation in the conditional error variation recommended. Therefore, we can adopt a discount factor to induce the time variation in $\boldsymbol{Q}_{t}^{(\boldsymbol{k})}$. Particularly, we do this by imposing a forgetting factor, $0<\beta \leq 1$, which enters the scale of the Inverted Range distribution, such as: $n_{t}^{(k)}=\beta n_{t-1}^{(k)}+1$. In this way, $H_{\boldsymbol{t}}^{(\boldsymbol{k})}$ is updated according to new data and information passed to reflect changes in volatility. This approach means that if $\beta<1$, the estimated time tof $H_{\boldsymbol{t}}^{(\boldsymbol{k})}$ is given as:

$$
S_{t}^{(k)}=(1-\beta) \sum_{s=0}^{t-1} \beta^{s}\left(\frac{S_{t-s-1}^{(k)} e_{t-s}^{2(k)}}{Q_{t-s}^{(k)}}\right)
$$

In other words, $H_{\boldsymbol{t}}^{(\boldsymbol{k})}$ takes the form of an exponential moving average (EWMA) and the oldest data is discounted over time. When $\beta=1$, then we retrieve $H_{t}^{(\boldsymbol{k})}=H^{(k)}$. The predictive mean of conditional $y_{t+1}$ in $\mathbf{Z}_{t}$, denoted by $\hat{\mathbf{y}}_{t-1}$. This is simply an average of each of the predictive means of the individual model, ie:

$$
\hat{\mathrm{y}}_{t-1}=\sum_{j=1}^{d} E\left[y_{t+1}^{(j)} \mid \mathbf{Z}_{t}\right] p\left(\delta_{j} \mid \mathbf{Z}_{t}\right)
$$

To which:

$$
E\left[y_{t+1}^{(j)} \mid \mathbf{Z}_{t}\right]=\sum_{k=1}^{p} E\left[y_{k, t+1}^{(j)} \mid \mathbf{Z}_{t}\right] p\left(\delta_{j} \mid \mathbf{Z}_{t}\right)
$$

The predictive density can be described as,

$$
p\left(y_{t+1} \mid \mathbf{Z}_{t}\right)=\sum_{j=1}^{d} p\left(y_{t+1}^{(j)} \mid \mathbf{Z}_{t}\right) p\left(\delta_{j} \mid \mathbf{Z}_{t}\right)
$$

To which:

$$
p\left(y_{t+1}^{(j)} \mid \mathbf{Z}_{t}\right)=\sum_{k=1}^{p} p\left(y_{k, t+1}^{(j)} \mid \mathbf{Z}_{t}\right) p\left(M_{k} \mid \delta_{j}, \mathbf{Z}_{t}\right)
$$

The posterior estimative is $\alpha_{t}$ (Equations 2 and $5)$ in DMA is data in the following way:

$$
E\left[\alpha_{t} \mid Z_{t}\right]=\sum_{j=1}^{d} E\left[\alpha_{t}^{(j)} \mid \mathbf{Z}_{t}\right] p\left(\delta_{j} \mid \mathbf{Z}_{t}\right)
$$

To which:

$$
E\left[\alpha_{t}^{(j)} \mid \mathbf{Z}_{t}\right]=\sum_{k=1}^{p} E\left[\alpha_{k, t}^{(j)} \mid \mathbf{Z}_{t}\right] p\left(M_{k} \mid \delta_{j}, \mathbf{Z}_{t}\right)
$$

$\left(y_{t+1} \mid \mathbf{z}_{t}\right)=O b s_{t+1}+\operatorname{Coef}_{t+1}+\operatorname{Mod}_{t+1}+T V P_{t+1}$

The first term (Obs) refers to observe variance, the second (Coef) represents the variance and the errors of the coefficients estimated by the model, (Mod) notes the variance due to the uncertainty regarding the choice of predictors e (TVP) a variance due to the uncertainty as to the choice of the degree of time variation in the regression coefficients.

\section{Vi. Application of the Methodology of THE DMA TO MOdel THE Direct INVESTMENT IN THE COUNTRY USING Exogenous Variable to THE Brazil Cost.}

As mentioned above, the Brazil Cost may imply a great obstacle to direct investment in the Country and consequently, the growth of the economy. We will use the Bayesian DMA method presented in section 5 to model the relationship between variables. The descriptive statistics of the series is available for observation in Table 1.

Table 1: Descriptive statistics of the monthly variations of the selected time series (IDP and Brazil Cost).

\begin{tabular}{c|c|c|c|c|c}
\hline \multicolumn{5}{c}{ Descriptive statistics of time series } \\
\hline Series & Mean & S. D. & Min. & Max. & Median \\
\hline $\begin{array}{c}\text { Direct } \\
\text { investment } \\
\text { in the } \\
\text { country }\end{array}$ & 0.074 & 0.429 & -0.665 & 1.651 & 0.002 \\
\hline $\begin{array}{c}\text { Tax revenue } \\
\text { (Gross } \\
\text { collect) }\end{array}$ & 0.064 & 0.111 & -0.971 & 0.590 & 0.064 \\
\hline $\begin{array}{c}\text { Electric } \\
\text { energy cost }\end{array}$ & 0.008 & 0.044 & -0.152 & 0.221 & 0.005 \\
\hline $\begin{array}{c}\text { Index on } \\
\text { world } \\
\text { interest in } \\
\text { corruption }\end{array}$ & 0.318 & 0.822 & -0.633 & 1.22 & 0.144 \\
\hline SELIC rate & 0.018 & 0.278 & -0.472 & 0.473 & 0.072 \\
\hline $\begin{array}{c}\text { Social } \\
\text { charge }\end{array}$ & 0.064 & 0.055 & -0.099 & 0.166 & 0.063 \\
\hline $\begin{array}{c}\text { Investment } \\
\text { in transport }\end{array}$ & 0.092 & 0.823 & -0.253 & 2.815 & -0.076 \\
\hline
\end{tabular}

The model described in equations 5 and 6 were applied in the monthly variations (month against the same month of the previous year) of the data described in the previous paragraph. The data cover the period from January 2012 to June 2018. For the application of the above model, we will use the R-project software and the DMA package. Before applying the model, it is necessary to verify the stationarity of the series used in 
the model. The increased Dickey-Fuller test applied to the seven variables; the result is described in Table 2.

Table 2: Stationarity test applied to the monthly variations of the selected variables.

\begin{tabular}{c:c}
\hline \multicolumn{2}{c}{ Dickey-Fuller augmented Test } \\
\hline Variable & P-value \\
\hline Direct investment in the Country & 0.001 \\
\hline Tax revenue (Gross collect) & 0.02 \\
\hline Electric energy cost & 0.0389 \\
\hline Index on world interest in corruption & 0.001 \\
\hline SELIC rate & 0,0387 \\
\hline Social charge & 0,0285 \\
\hline Investment in transport & 0,01 \\
\hline
\end{tabular}

As can be seen, we accept the alternative hypothesis, the stationarity one. The series containing the variances month against the same month of the previous year considered stationary and, we can apply the DMA model and study the dependency structure of the series. We used the Mean Out-of-Sample Error (SEM) and Mean Absolute Deviation (MAD) measures to test some lags for the explanatory variables. Based on this information, we use the lags presented in Table 3.

Table 3: Lags adopted in the modeling.

\begin{tabular}{c:c}
\hline Lags adopted in the model & \\
\hline Variable & Lags \\
\hline Direct investment in the country & \\
\hline Tax revenue & \\
\hline Social charge & \\
\hline Electric energy cost & \\
\hline Index on world interest in corruption & \\
\hline SELIC rate & 1 \\
\hline Investment in transport
\end{tabular}

It is worth mentioning that the model requires a period of adaptation to the sample; that is, a test period is required to better fit the model. In this article, the first ten months estimate were disregarded. Table 4 presents the specification adopted for the model.

Table 4: Specified adopted model.

\begin{tabular}{lll}
\hline & Specified adopted model \\
\hline $\mathrm{T}$ & & 65 \\
$\mathrm{n}$ & & 8 \\
$\mathrm{~d}$ & & 2 \\
$\mathrm{~g}$ & & 3 \\
& alpha & 0,990 \\
& Beta & 0,500 \\
& Delta & $0,1 / 0,59$ \\
Model Combination & 256 \\
\hline
\end{tabular}

As mentioned above, different combinations of parameters were tested. We initially considered two possibilities for forgetting factors, ie $\lambda=0.99$ and $\lambda=$

0.95. Given the greater factor, the results were more parsimonious; we adopted it, as shown in Table 4.
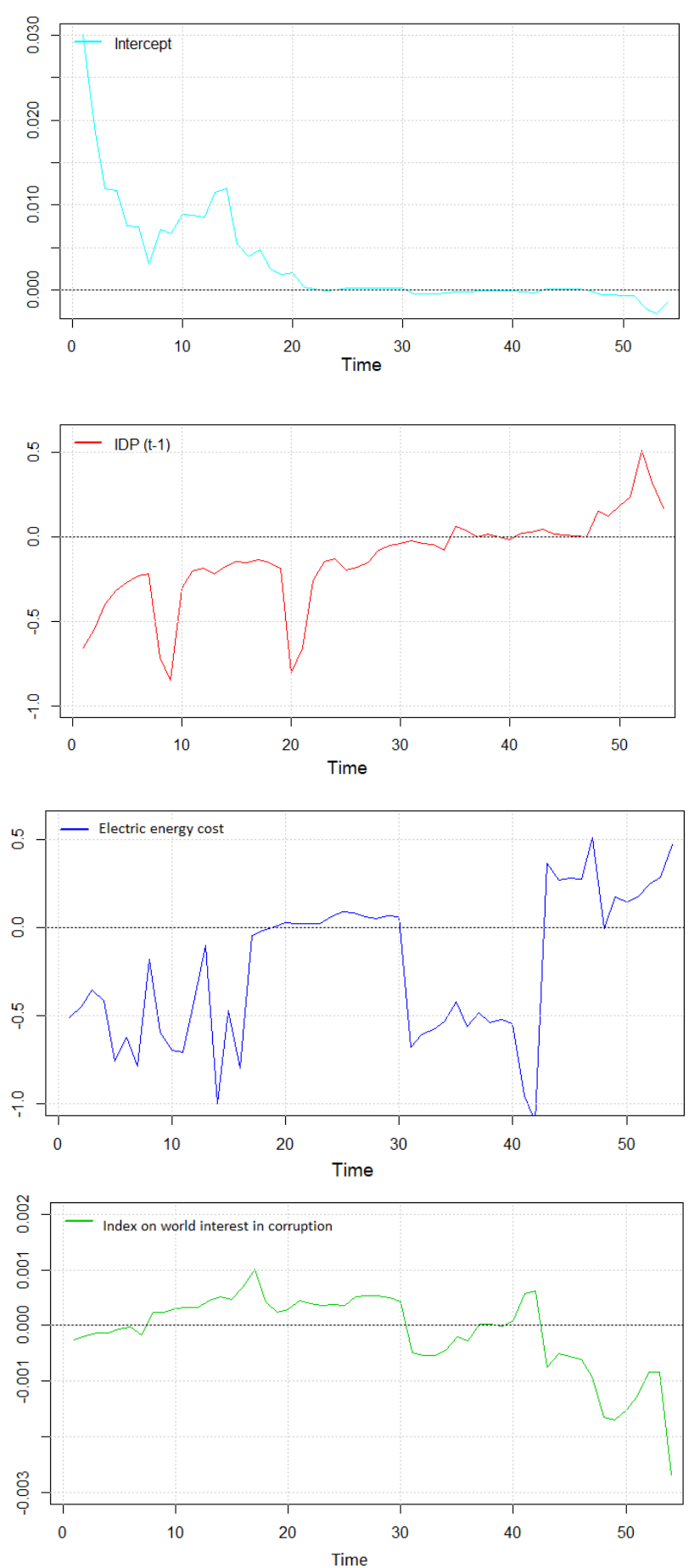

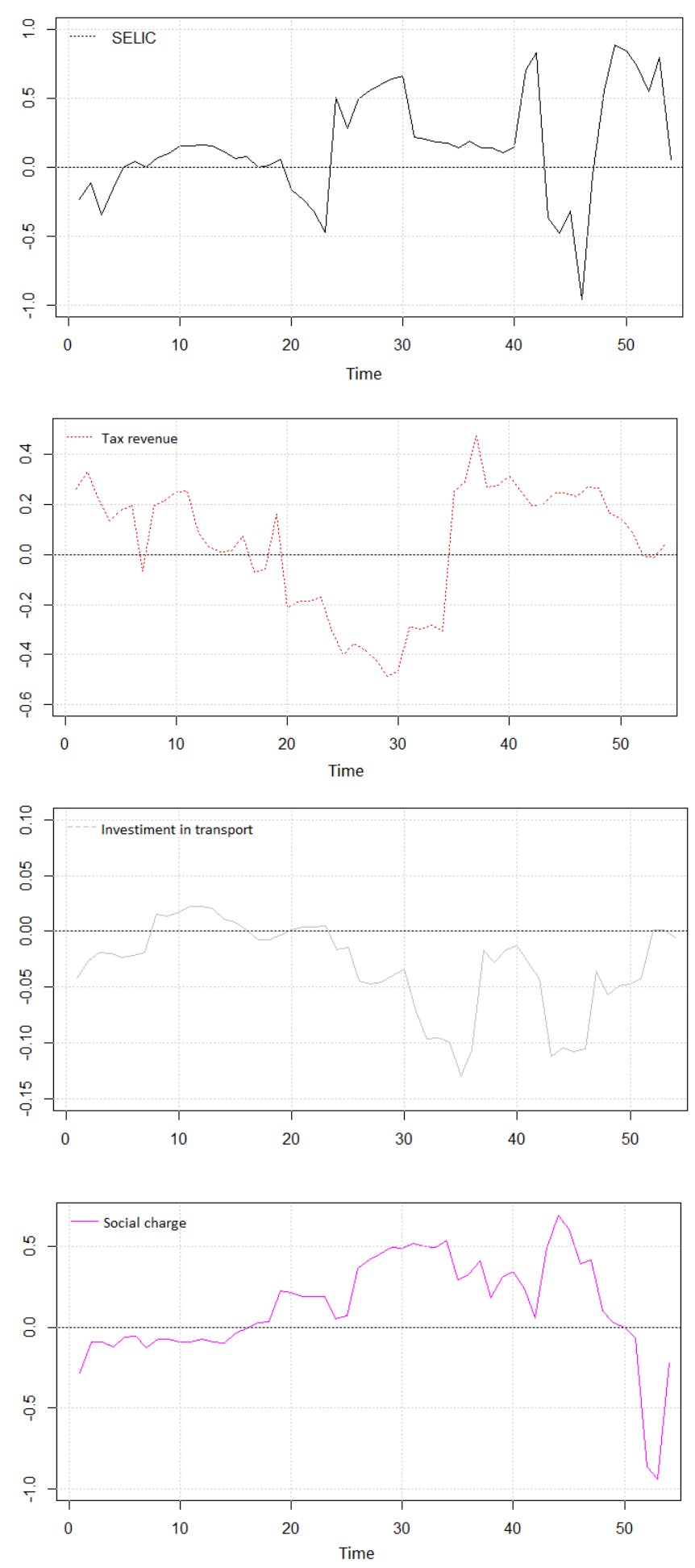

Fig. 1: Graphs of the posterior probability inclusions.

The charts show the importance of each return, at each point in time, for each of the variables. As can be seen, the charts contain the probabilities of later inclusion (the weights used by the DMA). That is, the probability of return in time $\mathrm{t}-1$ is useful for forecasting the time-dependent variable $t$. When analyzing the weights used by DMA (Figure 1), there is evidence of model change; that is, the set of regressors of the model changes over time. Some variables presented very small later probabilities of inclusion (coefficients very close to zero).

The intercept, the Corruption Index, and the Public Investment in Infrastructure and Transport. After this, we removed these variables from the model. However, we did not find improvements in the adequacy of the model to the data. Also, in the DMA, the changes can be gradual or abrupt. That is, there are many cases where the subsequent inclusion of probability associated with a regress of increases or decreases gradually over time, for example. We can verify abrupt changes mainly in the regressors: Cost of electricity, Taxation and SELIC Rate. As can be seen in the charts, over time, the explanatory variables (PPI, Electricity Cost, Interest Rate, social charges and Taxes) influence the Direct Investment in the country positively, or negatively, depending, possibly, of the conjuncture of the country.

The following table presents the statistical tests applied to model waste.

Table 5: Tests applied to Residues

\begin{tabular}{c|c}
\hline \multicolumn{2}{c}{ Statistical tests } \\
\hline \multicolumn{2}{c}{ P-value } \\
\hline Kolmogorov-Smirnov (normality) & 0.025 \\
\hline Anderson-Darling (normality) & 0.039 \\
\hline Box-Pierce (autocorrelation) & 0.579 \\
\hline Box-Pierce (autocorrelation - square) & 0.920 \\
\hline heteroscedasticity (Teste F Test) & 0.939 \\
\hline
\end{tabular}

According to Table 5, at the significance level of $5 \%$, the p-value did not suggest rejection of the homoscedasticity hypothesis. In the self-correlation tests, there is no evidence to reject the hypothesis in which the residues are de-correlation. In the normality tests, at the level of $1.0 \%$, the hypothesis of normality of the residues is accepted.

For purposes of comparison between the results (Backtest), we applied DMS and the VAR model with the fixed coefficient of variation. The measures (MAD and MSE) presented in Table 6. According to the literature, both models present a better prediction compared with other forecasting models. According to Lasse and Moller (2015) in the DMA, the model probabilities as weights to calculate the average forecast. The DMS puts all the weight in the model with the highest probability. The measures inherent to the models point to better adherence of the proposed model. 
Table 6: Adherence measurements

\begin{tabular}{|c|c|c|c|}
\hline \multicolumn{4}{|c|}{ Performance of applied models } \\
\hline \multirow[t]{2}{*}{ Measures } & & Models & \\
\hline & DMA & DMS & VAR \\
\hline $\begin{array}{c}\text { MSE (Mean } \\
\text { squared error) }\end{array}$ & 0.171 & 0.184 & 0.214 \\
\hline $\begin{array}{c}\text { MAD (Mean } \\
\text { absolute deviation) }\end{array}$ & 0.311 & 0.312 & 0.432 \\
\hline Likelihood & -23.923 & $24 . \overline{167}$ & 32.85 \\
\hline
\end{tabular}

The Dynamic Model Averaging has been used in several areas, with great possibilities for applications in Economics and Finance. In the present work, we used the DMA to model the IDP depending not only of its past but of six other variables - SELIC Rate, Electricity Cost, Taxes, Social Charges, Corruption, Infrastructure Investment transport - which according to the literature can influence the decision of the investor.

DMA models are widely used to generating parsimonious models, that is, models that involve the minimum of possible parameters to be estimated and that explain well the behavior of the response variable. In addition to this capability, DMA allows model parameters and specification to change over time. Comparing the performance of the DMA model with that of the DNS and the VAR model, we observed that the model proposed in this article presents satisfactory results. It presented smaller mean square error outside the sample and the smallest mean absolute deviation.

This paper highlights the importance of foreign investment in the Brazilian economy, and how much this is affected by internal factors, especially the cost of electricity, taxation, and interest rate. Most of the components of Brazil Cost were an obstacle to the entry of investment in the country. It is worth mentioning that many of these cost components could be mitigated by the implementation of public policies aimed at making the business environment more attractive and opportune for new investors.

\section{References Références Referencias}

1. BARBIERI, A., SILVEIRA, M. H. F. \& SILVA, A. S. B. da. (2014). Custo-Brasil e Investimento Direto Estrangeiro: uma análise de suas relações. Congresso nacional de excelência em gestão. Retrieved from http://www.inovarse.org/sites/ default/files/T14_0156_3.pdf

2. CAMPOS, F. de A. O. \& PEREIRA, R. (2015). Corruption and inefficiency in Brazil: An analysis of general equilibrium. Economic studies (São Paulo) 46, 2. 373-408.

3. CARMINATI, J. G. de O. \& FERNANDES, E. A. (2013). The impact of foreign direct investment on the growth of the brazilian economy. The Quarterly Review of Economics and Finance. N. 41, pp. 1.

4. CATANIA, L. \& NONEJAD, N. (2016). Dynamic model averaging for practitioners in economics and finance: The eDMA package. Journal of Statistical Software. 84. Retrieved from https://www.jstatsoft. org/ article/view/v084i11

5. DURBIN, J. \& KOOPMAN, S. J (2012). Time series analysis by state space methods, Vol. 38. Oxford University Press.

6. HADDAD, E. \& HEWINGS, G. (1998). Transportation costs and regional development: an interregional CGE analysis. European Congress of the Regional Science Association, 38. Áustria. Retrieved from http://www-sre.wu.ac.at/ersa/ersaconfs/ersa98/ papers/426.pdf

7. KOOP, Gary, \& KOROBILIS, D. (2013). Large timevarying parameter VARs. Journal of Econometrics 177, no. 2, 185-198. Retrieved from https://www. sciencedirect.com/science/article/pii/S03044076130 00845

8. MANCUSO, W. P. (2004). O lobby da indústria no Congresso Nacional: empresariado e política no Brasil contemporâneo. Revista de Ciências Sociais. Rio de Janeiro, vol. 47. Retrieved from http://www. scielo.br/scielo.php?pid=S0011-

$52582004000300003 \&$ script $=$ sci abstract\&tlng $=$ pt

9. PEIXOTO, B. K. da S. (2017). Previsão de retorno acionário: uma aplicação do dynamic model avaraging. Encontros Universitários da UFC 3, no. 1: 1791. Retrieved from http://www.repositorio.ufc. $\mathrm{br} /$ handle/riufc/33926?locale $=$ en

10. PERES, S. C. \& YAMADA, T. H. (2014). Determinants of Foreign Direct Investment in Brazil: an application of the Autoregressive Vectors model (VAR) in the period 1980-2010. Economics and Development. Vol. 2.

11. RAFTERY, A., KÁRNÝ, M. \& PAVEL E. (2010). Online prediction under model uncertainty via dynamic model averaging: Application to a cold rolling mill. Technometrics, 52(1), pp.52-66. Retrieved from https://www.ncbi.nlm.nih.gov/pmc/articles/PMC289 5940/

12. SANTOS, H. C. Z. A., SILVA, C., ARAUJO, T. A. \& ARAUJO, E. C. (2016). Empirical analysis of the determination of Foreign Direct Investment in Brazil for the period after 1990. Anpec, Vol. 1, pp. 5. 